\title{
Hubungan Indonesia Dengan Brunei Darussalam Melalui Kajian Inskripsi Pada Batu Nisan
}

\section{Achmad Cholid Shodrie}

Keywords: inscription, tombstone, Arabic script, Brunei Darussalam

\section{How to Cite:}

Shodrie, A. C. Hubungan Indonesia Dengan Brunei Darussalam Melalui Kajian Inskripsi Pada Batu Nisan. Berkala Arkeologi, 14(2), 227-233.

https://doi.org/10.30883/jba.v14i2.729

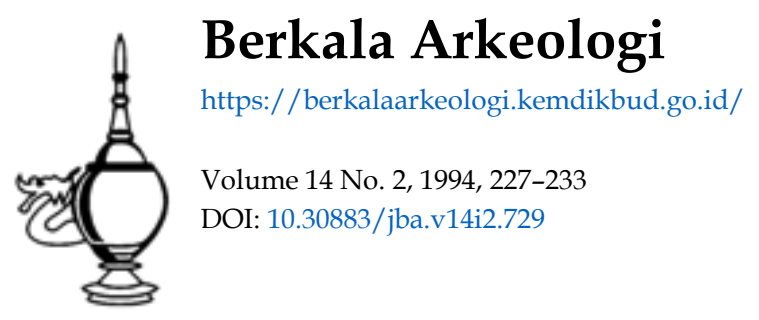




\title{
HUBUNGAN INDONESIA DENGAN BRUNEI DARUSSALAM MELALUI KAJIAN INSKRIPSI PADA BATU NISAN
}

\author{
Ahmad Cholid shodrie \\ (Pusat Penelitian Arkeologi Nasional)
}

\section{Beberapa temuan inskripsi dan bentuk batu nisan yang sama di Brunei Darussalam. \\ Batu-batu nisan/kubur dapat dikatakan se-} bagai sebuah prasasti masa Islam (Boechori, 1977) karena mengandung informasi sıapa dan waktu seseorang meninggal dunia. Selain itu ditemui silsilah keturunan dan dari mana asainya (Ahmad Cholid,1978). Begitu pula dengan temuan inskripsi pada pekuburan Bruneı Darussalam

Situs-situs pekuburan Brune terdapat di perbukitan mengikuti jalur dari alur sungai Brunei (mulai dari kampung Luba agak ke hulu) sampai ke muara atau sebaliknya. Kedua sisi sungai tersebut ditemui sekitar 30 (tigapuluh) buah situs perkuburan, dan lima di antaranya yang akan dibahas dalam makalah ıni. Kelima perkuburan tersebut adalah

1 Perkuburan Kota Batu

2. Perkuburan Residensı

3 Perkuburan Kubah Makam Dıraja

4 Perkuburan Uduk(g)-Uduk(g)

5 Perkuburan Buang Tengkuruk.

Dua dari lıma perkuburan tersebut berada di sebelah selatan dan berseberangan dengan situs perkuburan Kubah Makam Dıraja. Letak kedua situs perkuburan tersebut berhampiran dengan kampung Burung Pingalyang yang dipercayai sebagaı kota lama di atas air (Kampung Aır). Tiga situs laınnya berada di sebelah utara mengikut alur sungai Brunei. Berikut akan dijelaskan lebih terıncı mengenai kelima situs perkuburan tersebut

1. Perkuburan Kota Batu situs ini berada di sepanjang Kota Batu. Kota Batunya sendiri melatari hunıan Bruneı pada masa silamnya, karena dapat diartikar dengan perkotaan yang berbenteng batu. Hal itu ditunjang dengan temuan konsentrasi pecahan keramik di sepanjang sungai Brunei. Di bagian atasnya ditemukan batu-batu besar berbentuk empat persegı panjang, kubur-kubur yang dipercayal sebagaı makam Sultan Syarif Alı (1425-1432 AlSufrı, 1977) dan Sultan Bolkıah (1485-1524: Alsufri, 1977). Kubur-kubur tersebut memilikı kharısma tersendiri berupa kıjing makam, hiasan, dan kaligrafi

Sekitar $500 \mathrm{~m}$ ke arah timur (lereng perbukitan) darı makam Sulatan Syarif Ali, terdapat beberapa makam tiga diantaranya berdekatan. Tiga buah makam tersebut semula dikenal dengan nama makam Imam Ya'que saja Selanjutnya berdasarkan pada kajian epıgraf dari Mesı pada tahun 1984, terbaca nama sı matı nama tempat, dan suku Nama tempat yang disebut adalah Pinrang dan Makasar, sedang nama sukunya adalah suku Wajo dan Bugis. Ketiga makam tersebut ternyata saling terkait satu dengan lainnya. Hal tersebut terbuktı dengan penyebutan nama Ali Asfar, anak Imam Ya'qub. Imam Ya'qub anak Datuk Al-Faqih Abdu alrahman ibnu al-Qadi Pindrang Al-Waju-1 Al-Bugısı summa Al-Makasarı

Dua darı ketiga ınskrıpsi tersebut hampır sama terutama setelah tertulis nama dan bin darı yang meninggal itu Berbeda dengan nama ibn yang pertama seperti:

- Pada Imam Ya'qub (I.1) Inı diketahuı nısan Imam ibnu Al-Imam Hajı Al-Faqıh 'Abdurrah. man.

- Pada Alı asfar (I.3) Alamat nısan ını Ali Asfar, Ya'qub ıbn Hajı Abdurrahman.

Batu nisan yang ketıga merupakan penguat darı kedua inskripsi di atas. Ketıga-tiganya menyebutkan suku Bugis dan nama tempat Makasar Hanya pada batu nisan Ali Asfar tidak menyebutkan keturunan ketıga dan suku Wajonya tıdak ada Sedangkan pada batu nisan imam Ya'qub dan Al-Faqih 'Abdurrahman, dua suku Bugis dan Wajo tertera. Keıstımewaan batu nısan Ali Asfar, adalah dengan ditemukannya angka tahun wafatnya, tahun $1168 \mathrm{H}(1754 \mathrm{M}$ )

\section{Perkuburan Residensi}

Situs inı terletak di sepanjang jalan Resıdensı di pinggir Sungar Bruneı. Latar belakang penamaan jalan ını karena merupakan hunian orang-orang asıng yang menjabat resıden dı Bruneı. Lokası perkuburan ını terletak diperbukitan memanjang mengikutı jalur sungai Brune, dan bersambung dengan perbukitan Su. bo(u)k. Perbukitan Subuk sebetulnya termasuk daerah kota Batu sampai dı Bandar Sen Begawan. Perbukitan Subuk yang masih utuh dan belum terganggu pembangunan perlebaran perkotaan, karena di atasnya terdapat perkuburan-perkuburan Situs perkuburan ini menunjukkan persamaannya dengan bentuk-bentuk nisan yang ada di Aceh dan Riau. Dua bentuk nısan pada perkuburan in memilikı persamaan dengan perkuburan di Banten, yaitu yang 
terletak di bagıan belakang (sebelah barat darı cungkup makam Maulana Hasanuddin), tetapı bentuknya agak sederhana. Sedangkan sepasang lagi ditemukan di perkuburan di Keanggeh. Keletakan sepasang batu nisan ini bersisihan dengan makam dari Paduka Sultan Muhammad 'Ali Raja Bendahara Sri Indra Maharaja ibni Raja Bendahara Bungsu. Bentuk batu nisan Aceh lainnya yaitu bentuk batu nisan dari Minje Tujuh dan batu-batu nisan komples makam Batee Bale Samudra, Lhok Seumawe, Aceh Utara. Sayangnya dari inskripsi yang tertera pada abatu-batu nisan semacam ini belum diketahui siapa gerangan, tetapi data kronologisnya diketahui berkisar abad ke-16 M atau ke-10 H. Karena angka-angka tahun tersebut berkisar antara tahun 917 sampai tahun $930 \mathrm{H}$ (1523 M). Bentuk batu nisan semacam ini juga ditemul di kompleks makam Troloyo Nyi Ageng Maloko (Lasem) dan temuan baru di perkubur. an Ketapang Kalimantan Barat (informasi dari lbu Endang).

Persamaan bentuk batu nisan yang ditemukan di Brunei Darussalam dengan yang ditemukan di Riau, adalah batu nisan di makam Raja Ali Haji (Pulau Penyengat). Berbentuk bulat seperti kubah runcing dengan lekukan-lekukan di bagian bawahnya. Bentuk semacam ini ada juga yang pipih berbahan batu granit. Batu-batu nisan semacam ını ditemukan di perkuburan Kota Batu berada di dalam kompleks makam Sultan Bolkiah, kompleks makam Residensı, Kianggeh, Tumasek, Rangas, dan makam Diraja Persebaran batu-batu nisan semacam ini kebanyakan tidak berinskripsı, jadi kesulitan dalam menentukan sebagaı batu nisan Riau. Data yang membantu dalam penafsiran tersebut adalah adanya informasi bahwa ahli waris kubur ini selalu beriarah dan berasal dari Riau. Keletakan kubur yang sama dengan kubur Riau ını, menunjukkan sebuah pagoda pada batu nısan, jika ditarik garis lurus ke perkuburan sebelah selatannya. Bentuk batu nisan seperti yang ditemukan di Riau ini mempunyai dua bentuk, yaitu, bentuk bulat (kubur laki-laki), dan pipih (kubur wanita).

Bagian utara perkuburan Resıdensi, terdapat sebuah kubur Putri Abdul Majid, ditemukan sebuah kubur yang ada kaitannya dengan daerah dı Kalımantan Barat yaitu Pontıanak. Darı ins. kripsi yang terbaca menunjukkan bahwa yang meninggal adalah Tuanku Syarif Muhammad Hamit(d). Inskripsi selanjutnya menyatakan bahwa Syarif Abdurrahman ibni kepada Syarif Abdurrahman pulang ke nagari Fontianak. Sisi sebelahnya terdapat inskripsi waktu ia meninggal, tahun 1305 H (1887 M), pada tanggal 6 bulan RaJab, hari isnain, Jam 2 siang (III.a dan b)
Kawasan perkuburan Residensı sangat padat namun dari sekıan kubur yang berinskripsi hanya sebuah yang menyatakan berasal darı Pontianak. Letak kubur tersebut berjarak beberapa puluh centimeter dengan kubur Putrı Abdul Majid. Putri Abdul Majid dipercaya sebagai salah seorang Sultan Brunei yang wafat dı Cina. Perbandingannya memang menyolok antara dua makam/kubur itu. Hal tersebut bisa dimengeiti karena yang satu keturunan Sultan langsung, sedangkan Syarif Muhammad Hamid berasal dari rakyat biasa. Walau inskripsi yang tertera kemungkinan masih ada hubungannya dengan Sultan Pontianak. Sayangnya nama Sayid Abdurrahman tidak diikut nama Fam Al-Qadri, karena sultan Pontianak memakai nama Al-Qadri (Shodrie,1987)

\section{Perkuburan Kubah Makam Diraja}

Penamaan Kubah Makam Diraja dilandası alasan karena terdapat sebuah bangunan yang dikhususkan bagi dikuburkannya para Sultan Brunei, diantaranya adalah Sultan Omar Alı Saifuddin III (ayahanda dari Sultan HasanalBolkiah Muizuddin Waddaulah, sultan yang berdaulat sampai sekarang) yang berdaulat sampai tahun 1967. Bangunan itu beratap kubah, perkuburan tersebut rata-rata berbahan marmar pada kijing sampai batu nisannya Hiasan pada perkuburan in raya dengan kalıgrafi nama-nama mereka. Di bagian bawah diperuntukkan bagi kubur-kubur Sultan yang terdahulu sejak Sulatan Omar alı Saifuddin । (1740-1795). Kubur-kubur tersebut dapat dibedakan dari kubur familı dan sanak keluarga diraja. Batu nisannya besar dan tinggı-tınggı, dengan inskripsı yang mengukir nama para sultan tersebut. Lokasi perkuburan makam Diraja terdirı dari tiga bagıan, yang paiıng utara diperkırakan merupakan kubur darı orang-orang yang masih ada kaitannya dengan kolega atau kenalan Diraja. Temyata dari telaah pada batubatu kubur di makam Diraja ditemukan sebuan batu nısan yang berinskrıpsı nama Siti Fatımah Batu nisannya mempunyaı empat sısı dı bagıan badannya, sedangkan bagıan atasnya bulat runcing Hiasannya berupa suluran daun-daun iukut (istilah Brunei) dari batu pasır. Kempat sısı yang berinskripsı berurut darı sı sı selatan

- 6 baris, pada baris kedua, Siti Fatimah, baris ketiga binti Hafi Muhammad Sat-tu (Sabtu) Huruf yang terbaca terdiri darı sin. Tha dan Ta. Baris keempat al-haji Muhammad Shalih dari Mataram, kelima al-Jawi al-Magalangı keenam Fil Baruni (bahasa Arab)

- Sisi barat dengan 4 baris yang menerangkan tentang pembuatan batu nisan pada bulan Jumadil amwal tahun Wawu, kemudian 
berakhir pada bulan Sya'ban 1285 (bahasa Melayu)

- Sisı utara dengan 7 baris menerangkan tentang waktu meninggalnya Siti Fatimah pada 30 bulan Jumadil amwal, malam Sabtu sebelum tengah malam waktu itulah Siti $\mathrm{Fa}$ timah pulang ke rahmatullah (bahasa Arab).

- Sisi timur dengan 4 baris menerangkan pemberian batu nisan pada bulan Ramadhan wakafnya Muhammad Dawud (bahasa Melayu).

\section{Perkuburan Uduk(g)-Uduk(g).}

Situs ini berada di sisi sebelah selatan sungai Brunei, melalui sungai kecil masuk sekitar 500 $m$. Kemudian disambung dengan jalan kakı ke sebuah perbukitan. Lokasinya berdiameter sekitar 500 sampai $700 \mathrm{~m}$ di areal yang dimaksud. Terdapat beberapa kubur dan berbahan batu dan kayu. Orang yang disemayamkan di sana pada dekade akhir adalah beberapa syekh, seperti tuan Ali ibn Maulana Syekh Abdurrahman ibn Syekh Sulaiman ibn Syekh Mahmud ibn Syekh Ali bangsa Khan Negeri Yaman. Nama-nama syekh tersebut diketahui dari salah satu kayu nisan, yaitu Syekh Sulaiman (ada dua syekh yang sama namanya). Keistemewaan perkuburan ini adalah sebuah batu nisan yang mengandungi huruf lontara, di sebelahnya terdapat angka tahun $1272 \mathrm{H}$ (1855 M). Pada batu nisan tersebut terdapat 5 baris aksara Lontara, oleh Machi Suhadi (1986) dan Ali Fadhilah (Amerta No. 11, him. 50) menginterpretasikan sebagai berikut.

Salama rana (?)

naimpo tolatompu

ana'na anakoda

Cakotomo ri bela

Sedangkan melalui surat balasan kepada museum Bruneı, Ali Fadhilah mengalih-aksarakan sebagai berikut

la mo ne

naim poto

latoge ane

na an koda ca

katomoro Bala nipa

Terjemahan Machi Suh adı sebagai berıkut

"Soorang laki-laki yang bernama anak Nakhoda (Kapten kapal) bernama Cakatomoro yang berasal dari Balanipa (Sulawesi Selatan) (17 Nopember 1986)". Pada muka sebelahnya tersebut terdapat inskripsi lafad Taukhid dan angka tahun Hijrah nabi SAW 1272. Tulisan tersebut mengisi lukisan bintang segi lima yang dilingkari sedangkan pada lingkaran luarnya tertulis lafad Tauhid tersebut.

\section{Perkuburan Buang Tengkuruk}

Nama situs ini mempunyai arti tempat membuang tengkorak

Lokasi perkuburan agak menjorok ke dalam tepian sungai Brunei sekıtar $1 \mathrm{~km}$. Situs perkuburan ini terletak di sebuah perbukitan yang tidak begitu tinggi. Letak darı kubur-kubur ada yang di lereng-lerengnya dan di atas perbukitan. Sebagai tokoh utamanya dikenal dengan nama Datuk Ahmad. Kuburnya diberı cungkup bangunan kayu beratap genting. Melihat darı ukiran lubang-lubang angin dan ukiran yang menghiası kayu nisannya mengingatkan pada perkuburan di Kalimantan Selatan (Banjarma$\sin$ )

Inskripsi pada kayu nisannya hanya terdirı 3 baris saja. Pertama menyatakan langsung nama "Datuk Ahmad", baris kedua tertulis kalimat bulan Sofar dan baris ketiga angka tahun yang ditulis dengan angka Arab $1227 \mathrm{H}$ (1812 M) Mengapa Datuk Ahmad dijadikan tokoh utama dalam perkuburan Buang Tengkuruk? Dalam buku "Sudut Sejarah" yang diterbitkan oleh Muzium Brunei ternyata beliau adalah salah seorang ulama yang berasal dar slah satu kawasan di Indonesıa, yaitu Banjarmasin Datuk Ahmad adalah putera dari Hajı Abdui Latif yang datang ke Brunei pada masa pemerıntahannya Sultan Abdul Mu'mın (Sulatan ke-24 yang memerıntah tahun 1852-1885). Kalau dibanding. kan keterangan yang ada dalam buku "Sudut Sejarah" hlm.15, Datuk Ahmad bukan pada masa pemerintahannya Sultan Abdul Mu'mın kemungkinan pada pemerıntahan Sultan yang ke-21 yaitu Sultan Muhammad Kanzul Alam yang memerintah tahun 1807-1826 (Al-Sufri 1977)

\section{Data Lain di Batu Tarsilah Brunei Darusslam}

Batu Tarsılah mengandungı beberapa keterangan yang banyak sangkut pautnya dengan sultan-sultan yang pernah bertahta di Kerajaan Brunei Darussalam. Sejak Sultannya yang pertama bernama Sultan Muhammad Syah sampaı Sultan yang masih berdaulat sekarang (sultan ke-29)

Keterkaitan Batu Tarsilah sebagai batu prasasti masa silam di Bruneı Darussalam, merupakan data yang penting. Bagaimanapun corak dan bentuknya dan di manapun batu tersebut berada, merupakan data yang dapat berbicara tentang masa lalu Brunei Darussalam

Batu Tarsilah berbahan batu dengan bentuk pıpih berhias di bagian pınggır berupa suluran tumbuhan, dengan dua makam dan tulisan yang timbul. Muka pertama berisi 24 baris yang diawali kata-kata "inilah silsilah, raja-raja yang kerajaan. di nagari Baruni dinyatakan awal Datu imam Ya'qub ıya ... dan diakhiri dengan kalımat Srı Sultan Saifu at-Rijal 2 beranakkan... Muka 
sebelah laınnya diawali "Paduka Sri Sultan. Syah Baruni kemudian. saudaranya pula kerajaan. Paduka sn Sultan Hasan, ialah marhum di Tanjung maka anak. kemudian diakhiri kalimat Dal pada dua harı bulan Dzulhijjah pada harı Arba'a sanah 1221. Untuk muka kedua berisikan 26 barls

Hubungan Batu Tarsılah dengan pokok masalah yang menjadi topik makalah ini adaiah dengan ditemuinya nama Imam Ya'qub yang disebut sebagai penulis atau pembuat Batu Tarsıalah. Selain itu ada negerı dari wilayah Indonesia disebutkan dalam batu Tarsilah yaitu negerı Aceh dengan rajanya Mahkota Alam (pada barıs kedelapan)

Batu Tarsilah dapat dijadikan data otentik untuk menelusuri kronologis keberadaan kesultanan Brunei dengan para sultan. Nama Imam Ya'qub kemungkinan selama ini di Brunei belum dapat diketahui asalnya. Berdasarkan kajian epigrafi oleh epigraf Mesir terhadap inskripsı yang tertera pada batu-batu nisan di Brunei tidak diketahul artı Imam Ya'qub. Pakar tersebut hanya dapat membaca apa yang pernah dipelajari di negerinya, sedangkan perkembangan mengenai epigrafi di negerı lainnya tidak diketahuinya Dengan kata lain pakar tersebut tIdak mengetahul apa yang dimaksud dengan Pinrang. Wajo atau Bugis. Dengan demikian mereka tıdak bisa menjawab siapa Imam Ya'qub itu. Begitu pula dalam mengeja nama 'Ali Asfar, yang seharusnya inskripsi itu dibaca 'Ali Asfar dibaca menjadi istri imam Ya'qub (Simat, 1992: 7).

Keberadaan Imam Ya'qub yang dikatakan Simat hidup pada masa pemerintahan Sultan Muhyıddin (Sultan ke-14) rasanya sangat panjang usıa bellau, yaitu sekitar 500 tahun. Imam Ya'qub berasal darı daerah Sulawesı yang diperjelas dengan penyebutan daerah dan sukunya, maka tidak salah lagı bellau adalah seorang Bugis Wajo. PIndrang merupakan asal kakeknya yang menjabat seorang Qadi. Makasar kemungkınan sebagai daerah kelahiran beliau. Ditemukannya tiga buah batu nisan menunjukkan bahwa keberadaan keluarga Imam Ya'qub sampai beranak cucu

Asal daerah Imarn. Ya'qub adalah Makassar. Warga Makasar terkenal sebagal perantau yang melalang dunia Hal itu didukung dengan kenyataan bahwa kawasan Kerajaan Gowadi pada masa jayanya pernah menguasal hampir seluruh nusantara sampal di Australia. Begitu pula di kerajaan Melayu Raja Muda atau Raja Bendahara keturunan Bugıs Jadı keberadaan orangorang Bugis dı Brunei bukan merupakan hal yang aneh. Begitu pula halnya dengan keberadaan Datuk Haji Ahamad yang berasal dari Banjarmasin berperan sebagai orang yang diserahı tugas dalam kehidupan beragama di Brunei Darussalam. Orang-orang Banjarmasin berperan aktif dalam menyebar dan mengembangkan islam, sehıngga bukan hal yang aneh jika kemungkinan sampai ke Brunei Darussalam. Selain Itu Brunei dan Banjarmasin merupakan satu kawasan

Hubungan yang terjalin antara kerajaan-ke rajaan Islam di Nusantara pada abad ke-16 M, terutama dengan Aceh dan Riu tampak jelas. Hal tersebut terbukti pada Batu Tarsilah. Konotası tu. lisan dalam batu tersebut menyatakan "mengikuti perintah Sultan Mahkota Alam yang di neger Aceh", mengundang dua pendapat. Pertama Brunel berada di bawah kekuasaan Aceh, dan kedua kedudukan Brunei Darussalam sederajat. Begitu pula hubungannya dengan Rıau

\section{Penutup}

Hubungan yang terjalin antara Brunel dengan Indonesia ternyata tidak hanya dengan Jawa saja, karena dari inskripsı batu nisan me. nyebutkan beberapa daerah di Indonesia. Hubungan dengan kerajaan Mataram di Jawa ditunjukkan pada kubur Fatimah di perkuburan Diraja Selain itu nama kota(kabupaten) Magelang Hal itu ditunjukkan pada Inskripsi batu nisan

\section{KEPUSTAKAAN}

Abdul Halim Nasır, 1980, Makam-makam lama df Brunei Berita Muzium Bandar Seri Begawan, Muzium Brunei, Bilangan \& Januari March, him. 64-79.

Ahmad Cholid Sodrie, 1989, Ord Tomb Stone in Indonesia, Report on the sixth intra-Asean Archaeological Excavation and Excavation Work shop, Kota Batu-Brunei Darussalam (MS).

Awangku Karim bın Pangiran Othman, 1989, An introduction to Kota Batu Archaeological Site. Report on The sixth

Haji Awang Muhammad Jamil Al-Sufrı 1990 Tarsilah Brunei Sejarah awal dan perkembangan Islam Bandar Seri Begawan, Kementrian Kebudayaan Belia dan Sukan

Jawatan Kuasa Pameran Se jarah Perkembangan Islam di Brunei: 1970,Pameran Sejarah Perkembangan Islam di Brunei Bandar Serı Begawan

Mohammad All Fadhilah, 1989, Beberapa Catatan Tentang Lontara, AMERTA No. 11: Jakarta Depdikbud, 41 - 53

Simat bin Angas,dkk, 1992, Sudut Sujarah Tiokoh-lokoh Agama di Brunei Darussatam, 
Penegenatan Ringkas, Penerbitan Khas Bil: 23. Bandar Seri Begawan, Unit Penyelidikan Bahagian Sejarah/Epigrafi Jabatan Muzium.
Uka Tjandrasasmita, (ed), 1977,Sejarah Nasional Indonesia III, Jakarta, Depdikbud.

\section{Inskripsi yang ditemukan di perkuburan Kota Batu}

I1 HĀDĀ ULIMA MİSAN IMĀM

YA'QŪB IBNI AL-IMĀM HAJI

AL-FAQİH 'ABDU AL-RAHMAN IBNI

AL-QĀDIT FINDRANG AL-WAJŪ-I

AL-BUGİSİ SUMMA ALMANKĀSARİ

LATTAFA ALLĀHU ALAYHIM WAWALIŌ' ... (HIM)

ALMUSTAQBALI

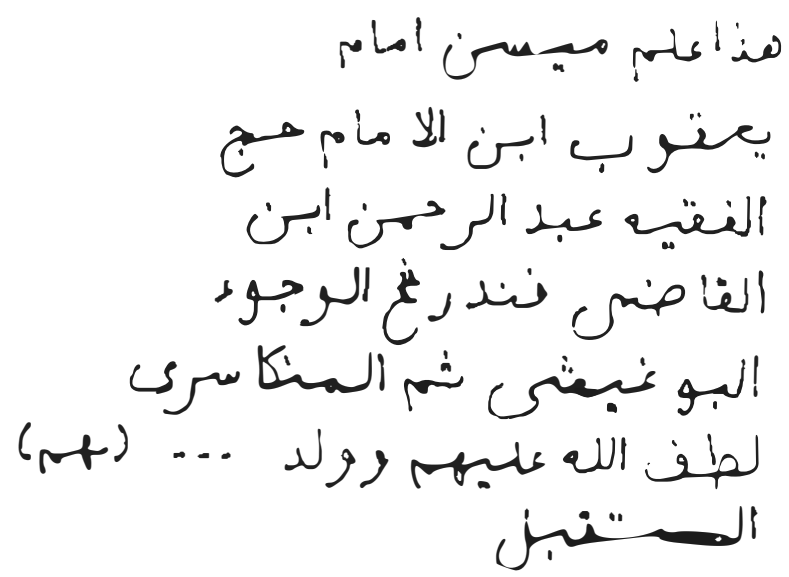

12 HĀDĀ AL ALAMĀTU

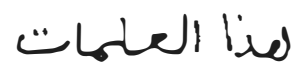

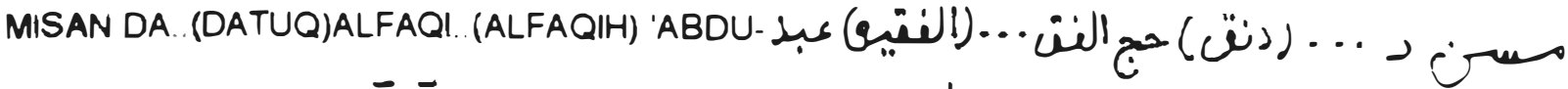
AL-RAHMAN IBNI ALQĀDİ .. (FIND) SART' LATTAFA ALLĀHU ... ('ALAYHIM-

WAWALIDIHIM ALMUSTAQBALI)

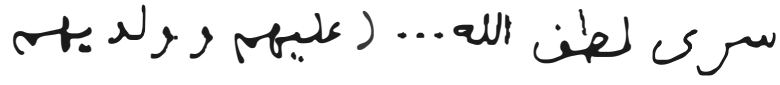<smiles>COC(=O)CCCI</smiles>

13 ALÁMATU MISAN INI

ALIT ASFARI IBNI IMĀMI YA'QŪB

IBNI IMÄM HAJI 'ABDU AL-RAHMANI ABUGISI

Co' ism is

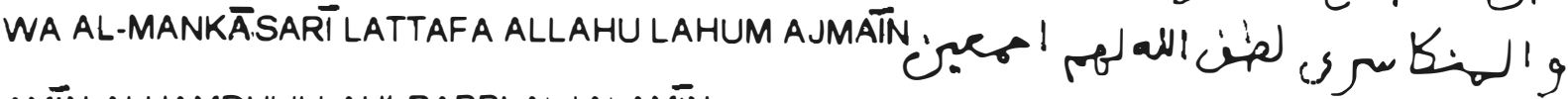
AMIN ALHAMDULILLAHI RABBI AL:' ALAMIN

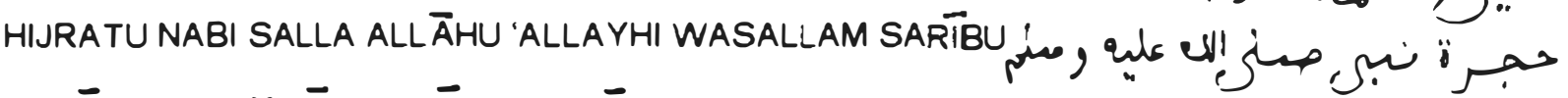
SARĀTUS ANAM FŪLUH DÜLAFAN TĀHUN

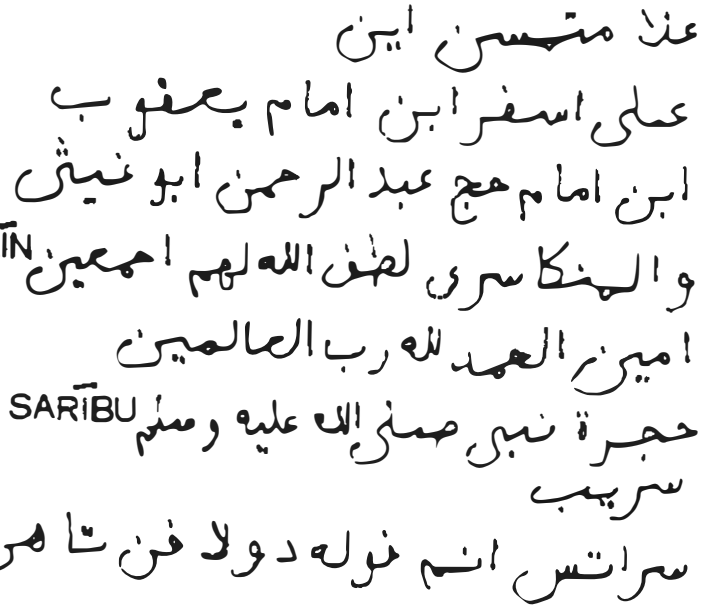




\section{Inskripsi yang ditemui di perkuburan Kubah Makam Diraja}

11.1. 'ALĀMAT ALQABRU

WA ALNISĀU SITİFÁTIMAH

BINTI ALHĀJIMUHAMMAD SAT-TU

ALHĀJ MUHAMMAD SĀLIH ALMATARAM!

ALJĀWI AL MAGALĀNGI

Fì ALBARŪNĀY!

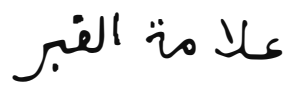

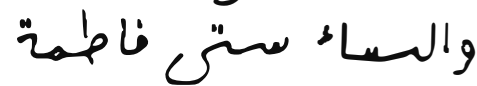

$$
\begin{aligned}
& \text {. }
\end{aligned}
$$

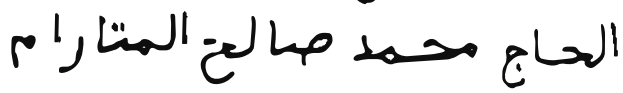

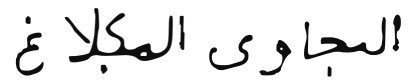

$$
\begin{aligned}
& \text { فو البر ونائ } \\
& \text {. }
\end{aligned}
$$

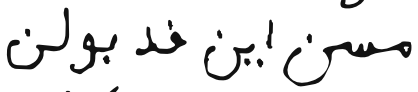

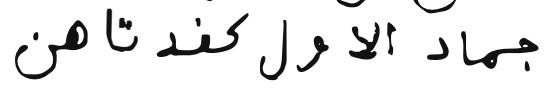

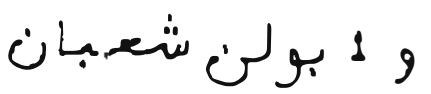

BAHWA DIPARBUWAT

NISAN INNI PADA BÚLAN

JUMĀDI ALAWWALI KAFADA TĀHUN

WA 1 BÜLAN SYA'BĀN

TARIKH SANATU

MIN HIJRATI ALNABAWIYYATI AL'ALAWIYYATI

WA FI SALĀSINA YAUMAN MIN SYAHRI JUMA

ALAWWALI FÍLAYLATI ALSABTI QABLA

ALNISFI ALLAYLI WA HĀDA ALWAQTU SITI

FÄTIMATU RAJA'AT LLA RAHMATI

ALL $\bar{A} H I$ MIN DĀRI ALFANĀ|

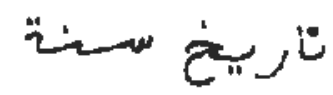

$$
\text { من مجر }
$$

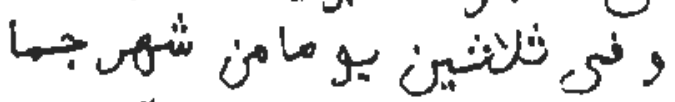

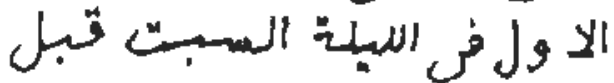

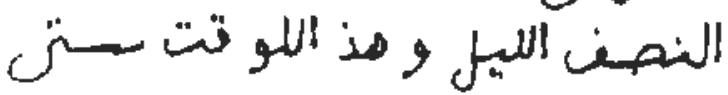

نا

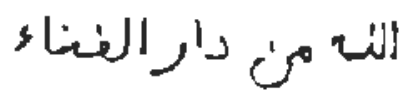

DIBARIKAN MISAN INI FADA BÜLAN

RAMADĀN WAKAFNYA MUHAMMAD DAWUD

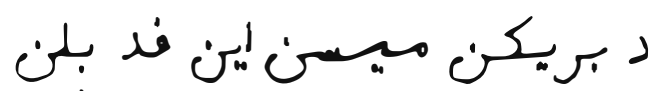

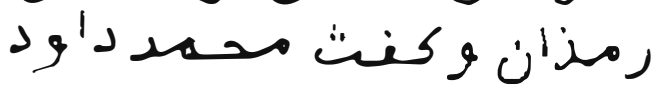


III.a. BAHAWA İNILAH 'ALĀMAT MĀ(I)SAN TUANKÜ SYARIF MUHAMMAD HAMITT ......(KÜMBALIT)

KARAHMATU ALL $\bar{A} H$ TA'ÁL' $\bar{A}$

SYARTF 'ABDOU AL-RAHMAN

IBNI KAFADA SYARTF 'ABDU AL-RAHMAN

YANG FÜLANG FADADA NAGARİFŪNTIYĀNAQ

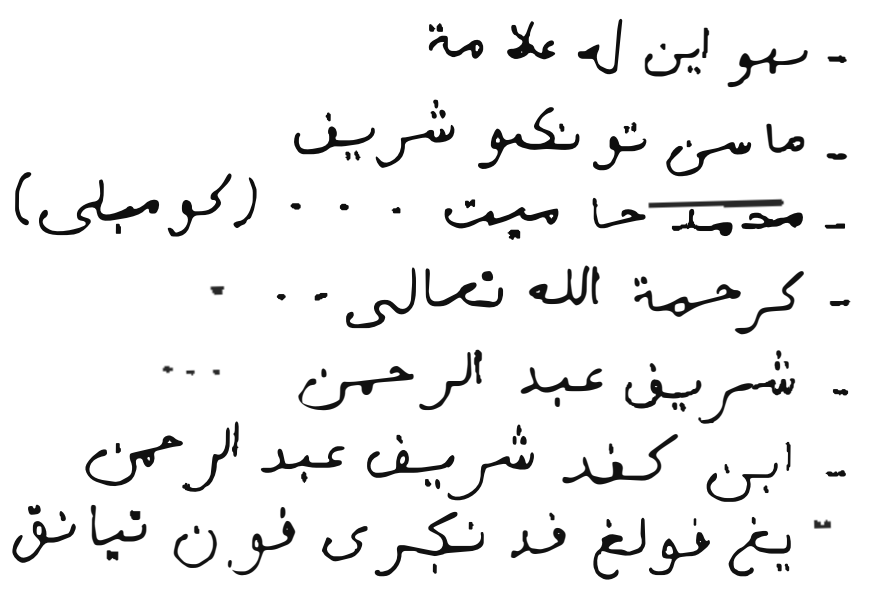

III. b. HIJRATU ALNABİ SALL $\bar{A}$

ALLĀHU 'ALAYHI WASALLAM

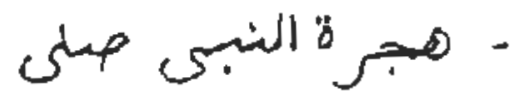

SERİBŪ TIGA RATUS LIMMA

TĀHUN KAFADA ANAM HĀRT

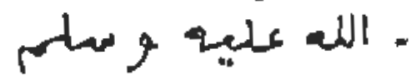

BÜLAN RAJAB HĀRT

ISNAYINWAKTŨ JAM FUKUL

DUA SIYANG TÄRIKKH

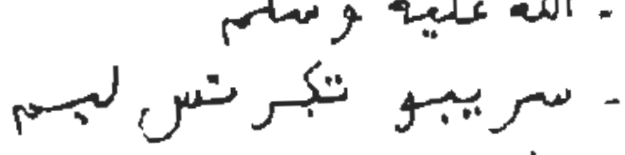

cos -

C.

SANATA 
